Madrygal. Revista de Estudios Gallegos

ISSN: $1138-9664$

\title{
Vinte anos do Centro de Estudos Galegos na Universidade do Minho (1997- 2017): balance e perspectivas de futuro
}

\author{
Fernando Groba Bouza; Noemi Basanta Llanes; Pedro Dono López ${ }^{1}$
}

Recibido: 11 de abril de 2019 / Aceptado: 15 de outubro de 2019

Resumo. Desde o ano da súa creación, en 1997, por medio dun convenio entre a Xunta de Galicia e a Universidade do Minho, o Centro de Estudos Galegos ten experimentado un proceso de inserción e consolidación progresiva non só no contexto académico da universidade bracarense, senón tamén en diferentes ámbitos da sociedade miñota, particularmente nos sectores vinculados á acción cultural. O labor desenvolvido polos diferentes lectores e lectoras do Centro contribuíu (e contribúe) non só para aproximar a realidade lingüística e cultural galega ao contexto do norte de Portugal, onde paradoxicamente é/era bastante descoñecida, senón tamén para favorecer a interacción entre axentes culturais de ambas as bandas do Miño/Minho. Abordamos nesta contribución a evolución da presenza do ensino da lingua e cultura galegas na UMinho, desde os cursos de extensión universitaria ás opcións que permiten chegar ao alumnado de múltiplos graos da oferta académica da institución, ben como ás diferentes actividades de divulgación organizadas, a miúdo en asociación con actores culturais relevantes da cidade de Braga, como a Rádio Universitária do Minho (RUM) ou a asociación cultural Canto d'Aqui: o programa de radio Galiza Mais Perto (RUM 97.5), a Semana Cultural Convergências Portugal-Galiza, o Dia da Galiza em Braga ou o Encontro Minho-Galiza son exemplo disto. Unha vertente á que quizais se teña prestado menor atención, a da investigación, deberá asumir un maior protagonismo en anos vindeiros, pois tamén se advirte a necesidade de estreitar vínculos no ámbito científico.

Palabras chave: Portugal; interculturalidade; difusión cultural; lingua e cultura galegas.

\section{[es] Veinte años del Centro de Estudos Galegos en la Universidade do Minho (1997- 2017): balance y perspectivas de futuro}

Resumen. Desde el año de su creación, en 1997, por medio de un convenio entre la Xunta de Galicia y la Universidade do Minho, el Centro de Estudos Galegos ha experimentado un proceso de inserción y consolidación progresiva no sólo en el contexto académico de la universidad bracarense, sino también en diferentes ámbitos de la sociedad miñota, particularmente en los sectores vinculados a la acción cultural. La labor realizada por los diferentes lectores y lectoras del Centro ha contribuido (y contribuye) no sólo a aproximar la realidad lingüística y cultural gallega al contexto del norte de Portugal, donde paradójicamente es/era bastante desconocida, sino también a favorecer la interacción entre agentes culturales de ambos lados del Miño/Minho. Abordamos en esta contribución la evolución de la presencia de la enseñanza de la lengua y cultura gallegas en la UMinho, desde los cursos de extensión universitaria a las opciones que permiten llegar al alumnado de múltiplos grados de la oferta académica de la institución, así como las diferentes actividades de divulgación organizadas, a menudo en asociación con actores culturales relevantes de la ciudad de Braga, como la Rádio Universitária do Minho (RUM) o la asociación cultural Canto d'Aqui: el programa de radio Galiza Mais Perto (RUM 97.5), la Semana Cultural Convergências Portugal-Galiza, el Dia da Galiza em Braga o el Encontro Minho-Galiza son ejemplo de esto. Una vertiente a la que quizás se le haya prestado menor atención, a la de la investigación, deberá asumir un mayor protagonismo en años venideros, pues también se advierte la necesidad de estrechar vínculos en el ámbito científico.

Palabras clave: Portugal; interculturalidad; difusión cultura; lengua y cultura gallegas.

\section{[en] Twenty Years of the Centro de Estudos Galegos at the Universidade do Minho (1997-2017): Balance and Future Perspectives}

Abstract. Since the year of its creation, in 1997, through an agreement between the Xunta de Galicia and the Universidade do Minho, the Centro de Estudos Galegos has undergone a process of progressive insertion and consolidation not only in

1 Universidade do Minho, Centro de Estudos Galegos.

Correo-e: fergroba@ilch.uminho.pt; noemibasanta@ilch.uminho.pt; pdono@ilch.uminho.pt 
the academic context of the university of Braga, but also in different areas of Miñota society, particularly in sectors linked to cultural action. The work carried out by the different readers of the Center has contributed (and contributes) not only to bring the Galician linguistic and cultural reality closer to the context of the north of Portugal, where paradoxically it is/was quite unknown, but also to favor the interaction between cultural agents from both sides of the river Miño/Minho. We address in this contribution the evolution of the presence of the teaching of the Galician language and culture in the UMinho, from the university extension courses to the options that allow to reach the students of multiple degrees of the academic offer of the institution, or to the different outreach activities organized, often in partnership with relevant cultural actors from the city of Braga, such as the Rádio Universitária do Minho (RUM) or the asociación cultural Canto d'Aqui: the radio program Galiza Mais Perto (RUM 97.5), Semana Cultural Convergências Portugal-Galiza, Dia da Galiza em Braga or Encontro Minho-Galiza are examples of this. One aspect that may have been paid less attention, that of research, should assume a greater role in the coming years, because it also warns of the need to strengthen links in the scientific field.

Keywords: Portugal; Interculturality; Culture Diffusion; Galician Language and Culture.

Sumario. 1. Introdución: algunhas notas sobre a historia do CEG. 2. Actividades de difusión cultural do CEG. 2.1. Programa na RUM. 2.2. Semana Cultural. 2.3. Festival Castro-Galaico de Nogueiró. 2.4. Dia da Galiza em Braga. 2.5. Encontro Minho-Galiza. 2.6. Exposicións e outras actividades na Biblioteca Lúcio Craveiro da Silva. 2.7. Presentacións de libros na Livraría Centésima Página. 2.8. Viaxes de estudos. 3. Novas propostas. 4. Coda. 5. Referencias bibliográficas.

Como citar: Groba Bouza, F.; Basanta Llanes, N.; Dono López, P. (2019): "Vinte anos do Centro de Estudos Galegos na Universidade do Minho (1997-2017): balance e perspectivas de futuro", en Madrygal. Revista de Estudios Gallegos 22, pp. 269-276.

\section{Introdución: algunhas notas sobre a his- toria do CEG da UMinho}

A conmemoración dos 20 anos de existencia do Centro de Estudos Galegos na Universidade do Minho constituíu unha efeméride que nos levou inevitabelmente a facer un balance do camiño andado, coa intención de reflectirmos sobre o traballo realizado e, en consecuencia, perspectivarmos novas apostas e propostas para o Centro $^{2}$. A pretensión é sempre, non fará falta dicilo, a de non só aproximar a realidade lingüística e cultural galega ao contexto do norte de Portugal, onde paradoxalmente é (se cadra xa será máis adecuado dicir "era") bastante descoñecida, senón tamén favorecer o (re)coñecemento mutuo e a interacción entre axentes culturais de ambas as bandas do Miño/Minho, aínda que desde os seus inicios a "Academia Minhota" estivo atenta ás relacións galego-portuguesas nos ámbitos lingüístico e cultural (cf. Aguiar e Silva 2017: 12). A proximidade xeográfica constitúe, no caso do lectorado miñoto, unha evidente oportunidade para favorecer a colaboración transfronteiriza que non se podía desproveitar, o que se viu potenciado por diversas iniciativas (eurorrexionais, do goberno autónomo galego) en prol dunha intensificación das relacións entre ambos os países.

O Centro de Estudos Galegos da UMinho, como acontece con moitos outros centros espallados polo mundo, comeza o seu andamento coa asinatura dun convenio de colaboración no ano 1997 entre a Xunta de Galicia e a Universidade do Minho, que se vén renovando periodicamente. O protocolo envolve o ensino da lingua, literatura e cultura galegas, a organización de "actividades relacionadas coa investigación, a promoción e a difusión da lingua, da literatura e da cultura galegas", coa integración no corpo docente do Instituto de Letras e Ciências Humanas dun lector que incialmente exercía funcións no CEG durante cinco anos e actualmente o período reduciuse a tres anos lectivos. Así, foron lectores do Centro Pedro Dono López (1997-2002), Iolanda Ogando González (2002-2003), Carlos Pazos Justo (2003-2008), Inés Rodo Montes (2008-2011), Marisa Moreda Leirado (2011-2014), Fernando Groba Bouza (2014-2017) e, na altura da redacción do presente texto, Noemi Basanta Llanes.

Coa contribución e o esforzo de cada un dos lectores citados, a oferta lectiva da lingua e cultura galegas, que comezou por marcar presenza nas actividades de extensión universitaria, integrando os chamados "Cursos Livres" da escola de línguas BabeliUM, inserida no Instituto de Letras e Ciências Humanas (ILCH) da Universidade, co paso do tempo acaba por aparecer nos planos de estudo da oferta académica

2 Destaca no ámbito da celebración do aniversario do CEG a preparación dun volume, por proposta do lector na altura, Fernando Groba, con contributos tanto de persoas e institucións que, dunha ou doutra maneira, estiveron vinculadas ou colaboraron co Centro durante todos estes anos, como tamén coa colaboración dos colegas da propia UMinho, dos antigos lectores/as do Centro e mesmo lectores doutros CEG espallados polo mundo. O libro está dispoñíbel en: http://cehum.ilch.uminho.pt/cehum/static/publications/galegos_no_minho.pdf. 
de primeiro ciclo en forma de materia optativa: primeiro, coa disciplina de Literatura e Cultura Galegas, que pode ser cursada polo alumnado dos diferentes graos do referido ILCH, e, máis recentemente, a opción de Língua e Cultura Galegas, que forma parte do conxunto de mateiras optativas, designadas Opção UMinho, que son ofrecidas a un amplísimo repertorio de licenciaturas das diferentes facultades (na realidade, reciben a designación de "Escola" ou "Instituto") que compoñen a Universidade e que ten tido unha importante acollida entre o alumnado.

A dimensión científico-investigadora probablemente sexa aquela que revela unha menor presenza ou expresión nas actividades do CEG en termos relativos. A título de exemplo, podemos lembrar a organización das Xornadas Galegas, das que se celebraron tres edicións nos primeiros anos de funcionamento do Centro ${ }^{3}$, ou as "aulas abertas", que contaron coa participación de especialistas de moi diferentes ámbitos da cultura galega. Esta dimensión poderá e deberá asumir un maior protagonismo en anos vindeiros, pois tamén se advirte a necesidade de estreitar vínculos entre alén e aquén Minho neste ámbito, mediante a realización, entre outras iniciativas, de encontros científicos que propicien o diálogo e interacción entre investigadores galegos e portugueses.

Se tivesemos que destacar algún aspecto do traballo realizado durante estes 20 anos, na nosa opinión habería que chamar a atención sobre a progresiva inserción, a partir dun ámbito puramente académico, na sociedade bracaranse (aínda resta o desafío de estender á cidade de Guimarães, onde se atopa un dos campus da UMinho, a acción do CEG) por medio dun abano amplo e consistente de actividades de promoción e divulgación, realizadas a miúdo en parcería con axentes culturais relevantes da cidade, o que reforza de maneira significativa o impacto das propostas desenvolvidas. Sobre as diferentes iniciativas do Centro, que tiveron como protagonistas, entre outros, a Antón Reixa, Chus Pato, Miro Villar, Ignacio Vilar, Gonzalo Navaza, Uxía, Anxo Angueira, Roi Casal, Ses ou Xabier Díaz, trataremos nos capítulos seguintes.

\section{Actividades de difusión cultural do CEG}

Os 21 anos que o CEG de Braga leva funcionando fan del un centro maduro que chegou á súa maioría de idade cunha traxectoria consolidada que conta cuns cómplices e actores socioculturais da cidade (para alén da propia universidade e dalgunhas das súas "Escolas") que teñen aumentado a repercusión e prestixio tanto do centro como de todo o que leva a cabo. En todo este traballo que leva facendo desde o ano 1997, se nalgo ten destacado esta institución, é nas actividades de divulgación e difusión cultural.

\subsection{Programa na RUM}

A primeira destas actividades é o programa radiofónico Galiza Mais Perto e ten como parceira a Rádio Universitária do Minho (RUM). A lectora responsábel do CEG de Braga é a encargada de facer un programa semanal en que se presentan novidades culturais galegas, os concertos da semana e onde se escoita música en galego de todos os estilos e xéneros. Loxicamente, por contexto e por situación xeográfica, adoita facerse especial fincapé en todas aquelas iniciativas e músicas que unen, dalgunha forma, as falas e culturas das dúas marxes da raia lusogalaica. O programa é emitido todas as cuartas feiras entre as 21.00 e as $22.00 \mathrm{hs}$. na frecuencia 97.5 e, ao mesmo tempo, en streaming ao vivo no sitio web http://rum.pt/ onde tamén pode ser escoitado en diferido no seu repositorio, de onde pode ser descargado libremente (http://rum. pt/shows/galiza-mais-perto). A ligazón de cada emisión vai sendo tamén comunicada a través do perfil de Facebook (https://www.facebook.com/ galizamaisperto/). Entre os programas emitidos, figuran entrevistas a persoeiros como a cantante Guadi Galego, o director do grupo Canto D'aqui (o señor Jaime Torres) ou incluso o presidente da Junta de Freguesias Nogueiró-Tenões (neste caso, con motivo da celebración do Festival Castro-Galaico, outra das actividades nas que colabora o CEG).

Ademais, desde hai uns anos, o Galiza Mais Perto ten colaborado coa asociación pedagóxica luso-galega Ponte Nas Ondas en diferentes efemérides como a celebración do Día Mundial da

\footnotetext{
Os títulos de cada unha destas Xornadas son elucidativos da orientación temática de cada unha delas: "Idade Média: Ponto de Encontro da Galiza e Portugal" (1998), "Relações entre Galiza e Portugal na Literatura" (1999) e "Aproximação à linguística galega". Interviñeron nas diferentes sesións, entre outros, especialistas do relevo de Ramón Lorenzo, Ramón Villares, Carlos Paulo Martínez Pereiro, Manuel María, Pilar Vázquez Cuesta, Ramón Mariño, Henrique Monteagudo ou Francisco Fernández Rei.
} 
Radio. O programa, preparado e gravado coa colaboración e participación do alumnado dos cursos libres de galego do Babelium, é emitido en diferido na propia RUM e en diferentes canles de emisión da Galiza como https:/www. radiofusion.eu/ ${ }^{4}$. Xa que logo, é de destacar o interese que ten espertado por esta iniciativa o programa "Emissão em português" da Radio Nacional de España (RNE) e que se materializou en dúas entrevistas realizadas pola actual lectora no mes de marzo 5 .

Esta colaboración (coa RUM) tamén lle serve ao CEG para publicitar, a través das ondas, todas as outras actividades que vai organizando e celebrando durante cada ano académico.

\subsection{Semana Cultural}

A segunda cómplice do CEG é a Asociación Cultural Canto D'aqui. Os seus membros levaban anos facéndolle homenaxes a un cantor portugués moi querido e valorado na Galiza (eles mesmos din que incluso máis do que o foi historicamente en Portugal), ao Zeca Afonso a través de diferentes propostas culturais e musicais. E, a partir do ano 2015, o CEG da UMinho comezou a colaborar tamén na organización dunha semana enteira onde se conmemoran, por unha banda, o pasamento do autor da "Grândola, vila morena" e, por outra, o nacemento da escritora nacional galega por antonomasia, de Rosalía de Castro.

Hogano a emisora de radio lusa Antena 1, a propia RTP, a Cámara Municipal de Braga, o Concello de Santiago de Compostela, a Rede da Galilusofonía, a Xunta de Galicia, a Fundación Rosalía de Castro, a Biblioteca Lúcio Craveiro da Silva, a Asociação José Afonso, forman tamén parte do comité organizador e colaborador deste macroevento que recibe asemade, desde hai uns anos, propostas de diferentes concellos limítrofes co de Braga para estender a iniciativa. Por el teñen pasado artistas, desde o lado galego, da altura de Uxía, Roi Casal, Iria Estévez,
Donicelas, Vudú, a Banda Municipal de Santiago de Compostela, Oîma e incluso un dos máis destacados da música tradicional actual, do Xabier Díaz. E, do outro lado da marxe, destacan: Daniel Pereira Cristo, Artur Caldeira, Celina da Piedade, Sebastião Antunes, o grupo Galandum Galundaina, a Banda de Música Militar do Porto (que incorporou no seu repertorio músicas de Rosalía e doutros músicos e poetas destacados da Galiza). A iso debemos sumar a presenza de figuras notorias da cultura de ambas as marxes como Eduardo Maragoto e Carlos Pazos-Justo, Henrique Barreto Nunes, João Veloso ou o propio Tiago Brandão Rodrigues, Ministro de Educación portugués, que se uniu a unha mesa de debate na $3^{\mathrm{a}}$ edición $^{6}$.

No ano 2018 a iniciativa foi merecedora do premio especial do xurado aRitmar Galiza e Portugal da EOI de Santiago de Compostela, á "Embaixada da Amizade Galego-Lusófona" por ter contribuído á divulgación da música e da poesía galego-portuguesa actuais, para achegar a cultura e a lingua dos dous países ao abeiro da Lei Valentín Paz-Andrade para o aproveitamento do ensino do portugués e os vínculos coa lusofonía, e teña tendido pontes de amizade entre os dous pobos irmáns?

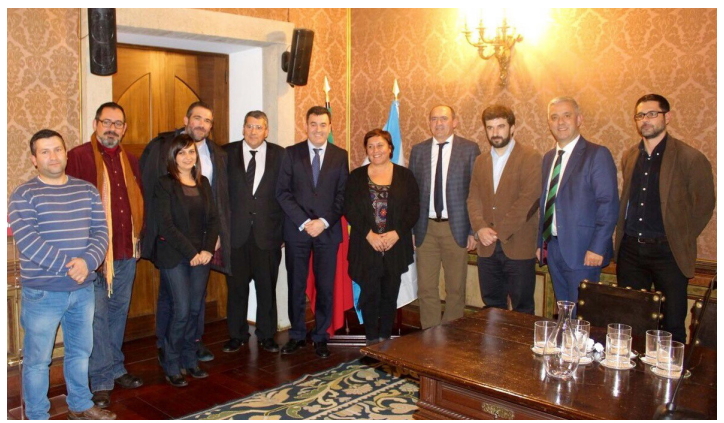

Figura 1. Detalle do coloquio da $3^{\text {a }}$ Semana Cultural. De esquerda a dereita: Fernando Groba (lector do CEG), Fernando Pena (membro da Asociación Canto d'Aqui), Marisa Moreda (exlectora do CEG), Pedro Dono (coordinador do CEG), António Cunha (reitor da UMinho), Román Rodríguez (conselleiro de Cultura, Educación e Ordenación Universitaria), Uxía (cantante), Anxo Angueira (presidente da Fundación Rosalía de Castro), Tiago Brandão (ministro de Educação), Valentín García (secretario xeral de Política Lingüística) e Carlos Pazos-Justo (exlector do CEG)

4 Os programas correspondentes ás edicións dos anos 2015 e 2016 poden ser escoitados aquí: https://soundcloud.com/ pontenasondas/galiza-portugal-mais-perto-especial-dia-da-radio-13-02-2015 e https://soundcloud.com/d-a-mundial-radio-2016/galizamaispertodiamundialdaradio-univeridade-do-minhobraga?in=d-a-mundial-radio-2016\%2Fsets\%2Fd-a-mundial-da-radio-2016.

5 Pódese escoitar de forma íntegra en: http://www.rtve.es/alacarta/audios/emision-en-portugues/emisso-em-portuguesprograma-radio-leva-sonoridades-galegas-portugal-04-03-19/5034349/?fbclid=IwAR0xUIcAPb5WW-P4cUPXb9 PAodzR4AtUicWJInAWNvV7U8dUhMdAluKB8JQ.

6 Tamén ten o seu propio perfil de Facebook: https://www.facebook.com/Convergencias.PTGZ/.

7 Pódese ampliar información nesta ligazón: https://www.facebook.com/aritmargalizaeportugal/posts/converg\% $\% 3 \% \mathrm{~A}$ Ancias-portugal-galiza-premio-especial-do-xurado-aritmar-galiza-e-portuga/1279990205468302/. 


\subsection{Festival Castro-Galaico de Nogueiró}

Tamén cos Canto D'aqui, o CEG colabora, desde hai arredor de 7 anos, no Festival Castro-Galaico de Nogueiró. Cada mes de xullo, nesta freguesía bracarense, confeccionan, no lugar do antigo castro, unha recreación castrexa ao tempo que teñen lugar concertos dos mellores grupos galegos e portugueses así como obradoiros prácticos de música, feira de artesanía, etc. ${ }^{8}$.

O festival foi premiado, no 2017, na XX edición dos Galardões A Nossa Terra, que convoca anualmente a empresa bracarense Direnor, na categoría de Evento?.

\subsection{Dia da Galiza em Braga}

A cuarta iniciativa en que está implicado o CEG da UM leva por nome Dia da Galiza em Braga e ten, quizabes, para alén do valiosísimo apoio loxístico do Mosteiro de Tibães (lugar no que se celebra desde a súa $3^{\mathrm{a}}$ edición no ano 2015), as colaboradoras e colaboradores máis especiais de todos: o propio alumnado da cadeira de Literatura e Cultura Galegas e incluso coa participación do alumnado dos cursos libres de lingua galega do Babelium Centro de Linguas.

Baixo a iniciativa e a supervisión do CEG, o evento é preparado nas aulas das cadeiras con todo detalle (ao tempo que se acompaña co programa da materia). A proposta consiste en asistir a diferentes actividades culturais que xiran arredor dun tema central anual (xa foron tratados, por exemplo: o Camiño de Santiago, a arte e a artesanía galegas, os xogos, as músicas tradicionais e o entroido). O evento inclúe desde conferencias (de especialistas ou dos propios estudantes), concertos, exposicións, obradoiros... para adultos até xogos e actividades para crianzas. Acostuma rematar cunha degustación de produtos gastronómicos típicos galegos onde as persoas dos dous lados do río acaban por compartir unha experiencia verdadeiramente memorábel.

Nomes como Francisco Díaz Fierros (naquel momento, vicepresidente do Consello da Cultura Galega), Bruno Villamor (gaiteiro e compositor), Paulo Jablonksi (historiador), o
Padre Fontes (famoso padre montalegrense), Mónica Noya (fotógrafa) ou Luís Martínez Romero (pintor), por citar algúns dos máis destacados, forman parte xa da historia desta actividade cultural que xa forma parte destacada da Agenda Cultural mensual da Câmara Municipal ${ }^{10}$.

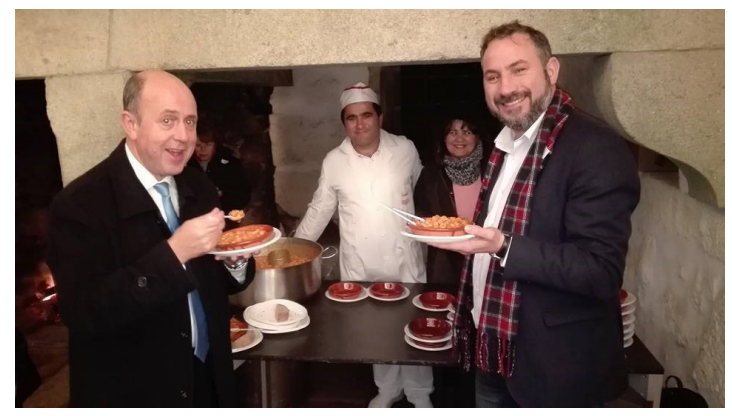

Figura 2. Detalle da degustación da $5^{\mathrm{a}}$ edición do Dia da Galiza em Braga, onde aparecen, entre outros, Firmino Marques, vice-presidente da Câmara Municipal de Braga, e Marcos Besada, alcalde do Concello de Salceda de Caselas

\subsection{Encontro Minho-Galiza}

A partir da idea de dous alumnos do CEG, Francisco Manuel Calado Abrunhosa e Adriana Silvério, e dun traballo que eles prepararan para a cadeira de Cultura Española co profesor Carlos Pazos-Justo (antigo lector do CEG), nace unha xornada de encontro e debate sobre temas culturais de actualidade na Galiza e Portugal (teatro, cinema, música) con expertos dos dous lados. Celebráronse, até o de agora, tres edicións. A primeira, no ano 2015, durou dous días e incluíu, da man da actriz canguesa Vanesa Sotelo, un repaso pola historia do teatro galego e das iniciativas teatrais que intentaron xuntar experiencias dos dous lados da raia e un obradoiro práctico. $\mathrm{O}$ segundo ano, durante un día, xuntou, na mesma mesa, a Nelson Zagalo (profesor do Instituto de Ciências Sociais da UM especialista en cinema actual), a Manuel González (vogal da Academia Galega do Audiovisual) e a Diana Gonçalves (autora, entre outros, do documental Mulheres da Raia) para falar do que máis saben: de cinema galego e portugués. E, o terceiro, xuntou, no auditorio de Goián (Tomiño), grandes especialistas na música galego-portuguesa: na parte matutina, a Jose Font (director da Radio Municipal de

Para máis información: https://www.facebook.com/castrogalaico/.

Véxase o web dos galardóns: http://galardoesanossaterra.direnor.pt/multimedia/edicao/20\#.

Para máis información: https://www.facebook.com/DiaDaGalizaEmBraga/. 
Tui), a Ricardo Almeida (gaiteiro e especialista na gaita de foles galego-portuguesa) e a José Vicente Simeó (director da Banda de Música de Monção) para debater sobre as músicas tradicional e popular; e, na sesión vespertina, a dous grandes da música actual, a Pedro Abrunhosa e a Ses, que desvelaron, entre outros, moitos dos segredos sobre as imposicións lingüísticas que esconde o panorama musical globalizado actual e fixeron público o compromiso de se coñeceren mellor e fusionaren os seus talentos ${ }^{11}$.

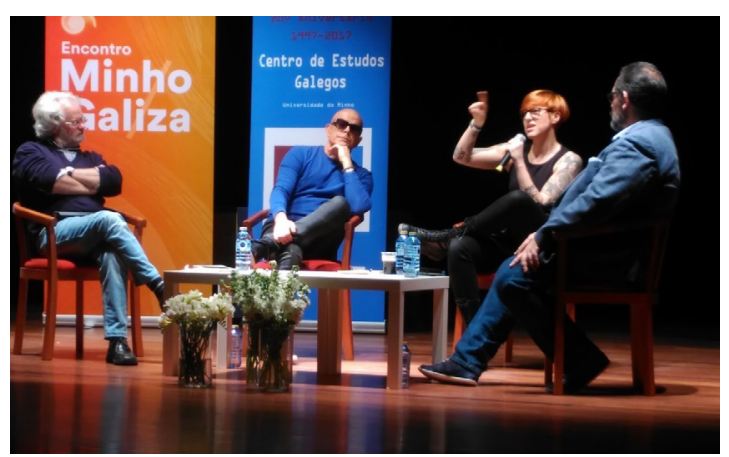

Figura 3. Detalle do debate vespertino da $3^{\mathrm{a}}$ edición do Encontro Minho-Galiza cos artistas convidados no centro: Pedro Abrunhosa e María Xosé Silvar (Ses)

\subsection{Exposicións e outras actividades na Bi- blioteca Lúcio Craveiro da Silva}

Outra socia incansábel e incombustíbel que leva anos e anos apoiando e colaborando co CEG é a dirección da Biblioteca Lúcio Craveiro da Silva, personalizada na súa directora Aida Alves. Esta institución, que ten dobre titularidade (da UMinho mais tamén da Câmara Municipal), leva albergado e participado en diferentes exposicións e presentacións de libros galegos na cidade bracarense. Destacamos diferentes exposicións que se fixeron na semana do 17 de maio para homenaxear os diferentes persoeiros festexados polo Día das Letras Galegas, outra sobre o poeta de Paradela (Lugo) Manuel Rodríguez López ou a propia presentación do libro dos 20 anos do CEG.

\subsection{Presentacións de libros na Livraría Cen- tésima Página}

O CEG ten tamén como compañeira unha das librarías máis famosas da cidade de Braga, a
Livraria Centésima Página (que está sediada no centro da cidade) ten deixado e publicitado moitas presentacións de libros a través do Centro de Estudos Galegos. Entre eles $A$ imagem da Galiza em Portugal do profesor Carlos Pazos-Justo, A imagem de Portugal na Galiza do profesor da USC Carlos Quiroga, Pico Sacro. Ferido polo lóstrego e a lenda con autor colectivo ou Sobre conflito linguístico e planificación cultural na Galiza contemporânea de Elías J. Torres Feijó e Roberto Samartim.

\subsection{Viaxes de estudos}

Por último, na fin do curso académico, desde hai xa uns anos, o CEG da UMinho, aproveitando a proximidade xeográfica con Galiza, premia, todos os anos, os seus alumnos e incluso aqueles cómplices que quixeren, cunha viaxe gratuíta en termos de transporte e aloxamento, que percorre, durante dous días, boa parte da xeografía galega con actividades de coñecemento cultural e xeográfico ${ }^{12}$.

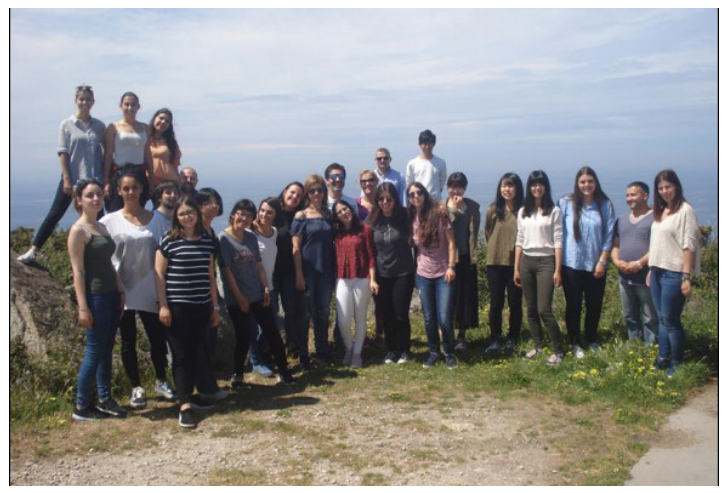

Figura 4. Foto de grupo no Faro de Fisterra na viaxe de estudos

\section{Novas propostas}

O camiño deseñado cara ao futuro só pode ser trazado despois de reflexionar sobre os pasos que se teñen dado. É nese sentido no que deberemos estabelecer dúas grandes direccións que apuntan, nun caso, cara ao continuísmo e, no outro, cara á procura de novas vías coas que divulgar e promover a lingua, a literatura e a cultura galegas no contexto bracarense.

Consideramos que o noso traballo docente debe ser avaliado de xeito moi positivo xa que, co paso do tempo, o Centro de Estudos

11 Para máis información: https://www.facebook.com/encontrominhogaliza/.

12 Para máis información, pódense consultar os dous perfís do CEG no Facebook: https://www.facebook.com/Centrodeestudosgalegosdauniversidadedominho ou https://www.facebook.com/ceg.universidadedominho. 
Galegos viu significativamente incrementado o seu alumnado nas diversas materias das que se responsabiliza. Tanto é así que, actualmente, a media anual de asistentes ás aulas supera os cincuenta. Dito isto, non só os datos estatísticos son motivo de orgullo senón tamén o notábel aproveitamento que o alumnado fai dos contidos e que se plasma nas enquisas de avaliación ofrecidas pola propia Universidade. Ben certo é que o contexto raiano ofrece a posibilidade de establecer pontes económico-sociais e histórico-culturais coa Galiza que seguramente sería difícil facer en moitos outros lugares. Non se trata dunha cuestión menor porque, explorar o coñecemento desde a realidade máis inmediata do alumnado, permite fomentar a motivación e tornar o proceso de aprendizaxe máis significativo. Esa é a opinión que en moitas ocasións teñen transmitido os nosos alumnos e alumnas cando afirman teren aprendido moito nas nosas aulas, non só sobre a Galiza senón tamén sobre ese Portugal norteño no que viven e do que, ás veces, se esquece a capital lusa.

A vinculación entre Galiza e a área miñota non só estrutura o deseño das nosas programacións didácticas, senón tamén a perspectiva coa que enfrontamos a adquisición dos contidos. O alumnado ten desenvolvido moitos e interesantes traballos, orientados cara aos seus intereses persoais e nos que exploraron, entre outras cuestións, as seguintes:

- Algúns períodos literarios galegos e portugueses, destacando as relacións persoais e literarias entre autores e autoras nacidas ás dúas marxes do Miño.

- Similitudes e diferenzas entre a lingua galega e o portugués do norte, atendendo ás aproximacións que desde unha perspectiva oficialista ou reintegracionista se realizan sobre a ortografía galega.

- Impacto cultural dos camiños de peregrinación a Santiago de Compostela, en particular o portugués.

- Relación entre entroidos galegos e portugueses como o de Lazarim, Podence ou Torres Vedras.

- Vestíxios do contrabando de alimentos e de wolframio na fronteira galego-portuguesa.

- Repercusión económica do grupo galego Inditex no norte de Portugal.

- Principais relacións de cooperación politico-económica no ámbito da eurorexión
Galiza-Norte de Portugal, destacando o proxecto Eixo atlántico do que Braga é agora capital.

$\mathrm{O}$ esforzo por achegar as dúas marxes do Miño presidiu tamén as numerosas actividades de difusión do lectorado ás que aludimos na epígrafe anterior e que actúan en paralelo á docencia universitaria. Quizabes sexa importante destacar, non só o seu progresivo crecemento e consolidación na cidade mais tamén a posibilidade que ofrecen de relacionar o Centro de Estudos Galegos con outros axentes culturais. A vontade de sumar forzas permitiunos propor actividades máis ambiciosas, facelas medrar e chegar a públicos que ultrapasan o estritamente universitario. Non menos importante é a notoria visibilización que ofrecen os medios de comunicación -radio, televisión e xornais- tanto bracarenses como estatais e incluso galegos cando se fan eco de todas estas iniciativas. O conxunto de todas elas constitúe, pois, o legado que nos deixaron os algo máis de vinte anos de lectorado da Universidade do Minho. Á súa vez, tamén son o pouso que nos dá forzas para emprender iniciativas novas e ambiciosas. Ese é o caso do "Ciclo de cine galego. Mulleres, patrimonio e sociedade" que neste ano comezará coa segunda edición. A súa estrea foi no ano 2018, con tres xornadas distribuídas ao longo do mes de abril nas que se proxectaron varios materiais audiovisuais, seguidos dun debate-coloquio e nos que se contou coa participación dos directores/as dos filmes e dunha figura representativa de cada unha das institucións organizadoras. De feito, un dos obxectivos que tiña e ten este evento é reforzar vínculos entre a Universidade do Minho a través da Vicerrectoría da Cultura e Sociedade e o Centro de Estudos Galegos, o Consello da Cultura Galega, a través da Comisión de Igualdade e a Sección de Patrimonio e Bens Culturais, e a Xunta de Galicia, a través da Secretaría Xeral de Política Lingüística. Os fíos condutores escollidos foron "mulleres, patrimonio e sociedade" porque, ao interrelacionalos entre si, remiten a temáticas transversais, de plena actualidade e gran preocupación social: a situación das mulleres e o empoderamento das sociedades rurais, así como a súa relación co patrimonio.

$\mathrm{Na}$ primeira edición proxectáronse cinco materiais audiovisuais multipremiados e asistiron ao evento os directores e directoras de cada un deles, tales como Álvaro Gago, Sara Traba ou Manuel Gago; e representantes das entidades organizadoras, así como especialistas dos 
diferentes temas tratados como Carla Cerqueira, María Xosé Porteiro, Beli Martínez ou Cristina Sánchez-Carretero. O ciclo foi un rotundo éxito por múltiples razóns: acadamos unha máis que satisfactoria implicación por parte de todas as entidades, a iniciativa foi acollida por unha inxente cantidade de público e obtivemos o recoñecemento do selo europeo no Ano Europeo do Patrimonio Cultural 2018 \#EuropeForCultu$\mathrm{re}^{12}$. Froito desta iniciativa foi tamén a sinatura dun protocolo de colaboración entre a Universidade do Minho e os cines Cinemax do Centro Comercial Braga Shopping nos que o evento tivo lugar. A segunda edición contempla aínda a incorporación do Instituto Camões ao conxunto de patrocinadores ao que xa aludimos.

\section{Coda}

A rede de Centros de Estudos Galegos constitúe unha realidade que contribuíu de maneira decisiva á difusión da lingua e cultura galega no mundo ao abrir a posibilidade de estudala en multitude de universidades diseminadas por América e Europa. Trátase dunha importante vía de visibilización que dispón o camiño para a súa promoción exterior e tamén para a actuación sobre numerosos estigmas que, aínda no século XXI, se asentan na desigual consideración das linguas. Non pretendemos en absoluto argumentar que a proxección exterior deba ser un medidor co que estabelecer xerarquías lingüísticas, mais si consideramos que promover unha visión positiva do galego nas voces de persoas estranxeiras pode contribuír a mostrar, tamén no país, o absurdo que é o abandono progresivo da lingua propia. Esa é, pois, tarefa do Centro de Estudos Galegos da Universidade do Minho que, ao longo de vinte anos, ten tecido unha profunda rede de traballo na cidade de Braga que incide mais tamén ultrapasa o ámbito académico.

\section{Referencias bibliográficas}

Aguiar e Silva, Vítor (2017): "O Centro de Estudos Galegos da Universidade do Minho: Entre memória e futuro", en F. Groba Bouza e P. Dono López (coords.), Galegos no Minho. 20 anos do Centro de Estudos Galegos na Universidade do Minho. Braga: Húmus.

Groba Bouza, Fernando e Pedro Dono López (coords.) (2017): Galegos no Minho. 20 anos do Centro de Estudos Galegos na Universidade do Minho. Braga: Húmus.

12 https://ec.europa.eu/programmes/creative-europe/actions/heritage-label en. 